\title{
Process Monitoring of Impacts Proposal for a New Approach to Monitor the Implementation of Structural Fund Programmes
}

Richard Hummelbrunner *

\begin{abstract}
$\mathrm{R}$ a monitorização de programas no quadro dos Fundos Estruturais, com base em experiência adquirida através da monitorização dos actuais programas e com base em perspectivas já anunciadas pela Comissão Europeia para o próximo período de programação. É justificada a necessidade de processos de monitorização - em simultâneo ou em alternativa ao uso de indicadores - e e apresentada com algum detalhe a 'Monitorização Processual de Impactos' ("Process Monitoring of Impacts") como uma abordagem alternativa à prática corrente de monitorização. Aplicações experimentais deste método na Áustria são descritas e ilustradas com alguns exemplos. São apresentados alguns resultados da experiência adquirida e a utilidade do método e comparada com a prática corrente de monitorização no programa INTERREG e outros programas do Objectivo 2. A secção final procura especificar como a 'Monitorização Processual de Impactos' pode ser aplicada no âmbito dos programas dos Fundos Estruturais no próximo período de programação.
\end{abstract}

Palavras-chave: monitorização; fundos estruturais; análise de impacto; avaliação processual; avaliação.

\section{Introduction: Why Process Monitoring of Impacts?}

\section{The challenge: impact analysis of complex programmes / projects}

Regional development today is increasingly characterised by the following features:

- Openness: At least in non-cohesion countries, regional policy is essentially dealing with open tasks, whose results cannot be known or forecast in advance. Improving competitiveness, promoting innovation etc. are open processes, where at the outset only general objectives can be defined, but concrete solutions and appropriate approaches will gradually emerge during implementation.

- Recursiveness: The success of regional policy depends on the interaction of economic, social, cultural and physical resources within a territory and on the quality of collaboration between key actors having access to or being responsible for these resources. These actors appear on the supply and on the demand side of regional policy (as suppliers they mobilise the resources, as project owners they want to tap added value from the co-ordinated use of these resources).

- Unpredictability: The key players in regional development processes (providers as well as recipients of support measures) are social actors (institutions, individuals). Their actions are not just the result of pre-defined and explicit objectives, but also of their (often hidden) specific motives and interests, as well as (organisational, social etc.) rules which determine their behaviour pattern.

Impacts of regional development projects / /programmes are the product of internal as well as external factors and their interrelations. It is difficult to identify clear, obvious relationships, because impact chains emerge in a dense set of actors which can exert influence on its various

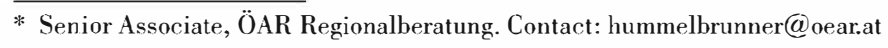


elements - and are mutually influenced by them. In order to achieve expected impacts, it is crucial that involved actors keep focused on them and adequately adapt during implementation in order to take account of changing conditions.

Conventional approaches to impact analysis are not well suited for these complex and dynamic conditions, because they aim at identifying a "linear" progression of effects (e. g. output leading to results leading to impacts) which take place quasiautomatic, i. e. irrespective of the actors involved, their interests, resources and power. Or they attempt to isolate the effects of individual activities (e. g. a measure or programme), which becomes increasingly difficult (and costly) with dense and intertwined effect patterns.

Besides, it is very tempting to claim observable impacts, regardless whether the project / programme under question has actually contributed to their achievement. This is particularly tempting in the case of higher-level objectives, where contributions of single factors are easy to claim - but difficult to (dis)prove (i. e. the contribution of a training measure to increase employment in a given territory). Or in the case of long impact chains, where causes and effects are rather distant from each other, either in time or in functional relations.

Moreover, these types of impact assessment produce little information which is relevant for the management of on-going projects / programmes. On one hand, because the information arrives rather late, which is particularly true for assessments which rely on impact indicators, where information can only be produced once an indicator (and / or the respective quantitative target) has actually been met. On the other hand when - due to the "attribution gaps" - the actual contribution for the achievement of impacts remain unclear and does not provide clues on "whether things have been done right or the right things have been done" which are the main sources for identifying areas of improvement!

\section{The need to monitor processes in SF-Programmes}

Management of regional development programmes can be regarded as steering of interlinked processes. At the core are primary ("value creating") processes, i. e. those activities which are directly responsible for producing desired outputs. In Structural Funds (SF) Programmes these primary processes usually consist of projects, which are implemented by (public or private) project owners for whom a programme provides resources.

Basically the primary process of projects is carried out by the project owners. They develop ideas, define their specific project objectives, invest own resources and assure that internal and external conditions are met in order to achieve the desired effects. Their core value is performance, i. e. efficient production of outputs in given (and changing) circumstances and with minimum interference from outside.

In public programmes (e. g. SF) other social systems (administrators, politicians, professionals) are involved as well, who have their own objectives and values which determine their behaviour. They try to influence the projects and the behaviour of other actors (e. g. decision-making of administrators, support for project owners through lobbying or advice).

The influence of these other social systems differs between programmes: some are strongly influenced by politicians (often with administrators as close collaborators), others are dominated by administrators and professionals. These then tend to be "technocratic" or can even lead to situations where the entire process is driven by administrators and/or consultants, looking for project promoters to carry out their ideas.

- In a more abstract form, projects in $\mathrm{SF}$ Programmes are the outcome of four interacting social systems with distinct objectives and values as well as multiple relationships: 
Figure 1 - Social systems involved in SF - projects

These social sub-systems can be located at various levels (e. g. EU, national, regional). And they differ in their functions, objectives, information needs and time frames:

- Political subsystems: They assure a balance of interests to safeguard the acceptance of decisions, decide on the allocation of funds and define objectives in a rather simplified, often symbolic or even ambiguous manner. They require similar information that can be easily communicated, notably visible and tangible effects within rather short time frames.

- Administrative subsystems: they define the formal "rules of the game" during implementation and assure a stable regulatory framework for project owners, need to safeguard transparency and prevent irregularities. They require information which is controllable and unambiguous in order to fulfil reporting tasks towards the political system or the wider public. Thus they need quantifiable data within a given programme period.

- Professional subsystems in different domains with different degrees of involvement (consultants/evaluators with contractual interests, "observing" experts). They aim for sound interventions according to professional standards and solid operational targets which can be monitored along standards of validity and relevance, with less concern on constraints in terms of cost and time. They are interested to also look at invisible and intangible effects, or effects beyond the boundaries of a programme period.

Programme management needs to reconcile the logics of these interdependent sub-systems, and to make sure that the information needs of all actors are met. This usually requires extracting information from project owners, who are well informed about their project, but need to be convinced (or obliged) that other actors, who are not involved as directly, also need / want to know about these activities.

However, conceiving management in this way also has consequences for monitoring practice and would in particular require a shift from the prevailing monitoring of indicators towards the monitoring of processes, essentially for the following reasons:

- Since the management focus is on processes, monitoring should do the same, if it is to provide meaningful information. Observation of a few isolated indicators (even if they are quantified) provides little information on the actual functioning of projects / programmes and the mechanisms which are crucial for producing desired effects. 
- Indicators are not well suited for complex situations as they only capture a narrow part of reality, reflect isolated phenomena and lead to wide-spread preference for measurable data and short-term effects. Moreover, there is a risk that indicators are (mis)used as substitutes (and not as observation tools) for stated objectives.

- Attempts to monitoring programme implementation only via indicators lead to overly ambitious monitoring systems, which contain vast quantity of data, require advanced technical solutions which are often unstable and unreliable - and still lack many aspects which need to be understood in order to effectively steer the implementation process.

Overloaded monitoring systems are also the consequence of confusing the logics and information needs of the involved sub-systems: When administrators request data regardless of their availability or professional validity, when project owners are assumed to share programme objectives and thus provide information freely, when objectives stated at political level are mistaken as "professional" operational targets.

This mixture of logics is inherent in SF Programmes: whereas strategies and measures are defined from a professional point of view (within a context defined by administrators and politicians), monitoring systems and the corresponding indicators are established with the intention to provide data which satisfy administrative - and even political - information needs.

However, the different interests, resources and powers of the involved sub-systems not only explain differences between "soft" and "hard" measures, they also have considerable influence on the achievement of effects in general. They can explain why effects do not take place in "linear" progression (output leading to results leading to impacts) and provide the rationale for interruptions or deviations of such an intended sequence.

\section{Rationale for a different monitoring approach for SF - Programmes}

Present Monitoring Systems in SF - Programmes are essentially input driven and focused on input and output indicators. And Monitoring has become a demanding task, which consumes substantial time and resources from monitoring staff who process data and produce reports, from programme authorities who assure data input - and from project owners who are requested to provide this data, mainly via reports.

But the utility of these efforts is limited and increasingly being questioned:

- Although quantified (output) indicators might be useful for reporting to other entities (e. g. EU Commission, Managing Authority), they have little meaning for the implementing agents, because per se they lack explanatory value and cannot be used to derive information needed for improving performance in implementation.

- Attempting to monitor programme implementation only via indicators lead to overly ambitious monitoring systems, which contain vast quantity of data, require advanced technical solutions which are often unstable and unreliable - and still lack many aspects which need to be understood in order to effectively steer the implementation process.

- There is (too) much deadweight information contained in Monitoring Systems, data which is collected without clear uses or users. And this situation is even more unsatisfactory when taking into account the vast amount of information collected from project owners in the form of reports, which are mainly archived and only to a very limited extent analysed (e. g. by evaluators).

In addition, monitoring - and corresponding reporting - based on outputs and deliverables can lead to a rather inflexible framework for implementation. Especially when this is done in a mechanistic manner, as is the case in some INTERREG IIIB Programmes (e. g. CADSES). Projects are then required to act in conformity with their original applications and are made accountable to strict implementation of planned activities within predefined milestones. And any deviation is per se regarded negative, has to be approved and often leads to renegotiations or even modifications of contracts.

This neglects the need to adapt to changing circumstance in order to ultimately achieve project objectives and results and is based on the assumption of a "linear" progression of effects (e. g. output leading to results leading to impacts) which take place quasi-automatic, i. e. irrespective 
of the actors involved or contextual conditions. But this assumption is hardly valid under the complex implementing conditions of INTERREG projects: Carrying out activities as foreseen is by no means a guarantee that expected results let alone impacts will be achieved, as there are many other (external or internal factors) which are of importance.

The problems and limits of present Monitoring Systems as described above are widely acknowledged by programme authorities and practitioners in the Member States, but also by the EU Commission:

- The Draft Structural Fund Regulations foresee in line with a more strategic orientation in the programming documents - a clear focus of Monitoring and Evaluation towards impact and strategic goals. Article 45 in particular stipulates that "Evaluations shall appraise the impact Fund assistance and the implementation of operational programmes with respect to the strategic objectives of the Community, to Article 158 of the Treaty and to the specific structural problems affecting the Member States and regions concerned."

- The new "Working Paper on Indicators" recommends to complement present input driven Monitoring Systems with a more impact-led approach. In this respect section 3.3. emphases result indicators as a core instrument for programme management: "The difficulty is that impact indicators by their nature are often available only after a considerable time lag and they often need substantial methodological input in order to be valid. Output indicators, on the other hand, deliver only information about the physical, not the socio-economic, effects of an action. In practical terms this gives a special importance to result indicators for the management of a programme as a whole during the implementation of an intervention. Therefore the Commission wishes to encourage the Member States to concentrate their efforts on the improvement of the quality of this category of indicator".

For some programmes the Working Paper suggests to put more emphasis on process aspects. In Section 4.6. it is recommended to "pay special attention to process issues and use them for monitoring and evaluation". Moreover, "indicators are just another instrument for effective management with an intrinsic potential and limitations. For instance, indicators may distract the attention of programme managers from important, but unexpected impacts or from major process issues. Therefore for some actions (e. g. support for RTD, innovation, territorial cooperation) it might be especially difficult to collect meaningful information on results and impacts. Here the collection of process-related information, on the development of capacities and competences of stakeholders can be an instrument to support programme managers in their management and reporting".

But the approach proposed in this Working Paper essentially foresees an increase in the use of result and impact indicators as well as better quality for strategic indicators through more refined methods for identifying and quantifying them. As explained at the beginning of this paper, the use of indicators has only limited value for capturing impacts, because indicators only capture a narrow part of reality, reflect isolated phenomena and information on impact indicators in particular arrives rather late.

Moreover, impact achievement is a doubtful measure for the effectiveness of a programme. As shown in the following figure, there is usually a trade-off between the influence of a programme and other actors or external effects over time: 
Figure 2 - Lines of influence in Structural Fund Programmes

Source: Adapted from S. EARL, E. CARDEN, F. SMUTILO “Outcome Mapping”

The influence of a programme is strongest in the early stages, where inputs and their conditions are defined or activities can be foreseen by programme authorities (e. g. information of target groups, support for project generation) which should lead to desired outputs (i. e. projects). But this influence then decreases over time and the influence of other actors (e. g. implementing partners, project owners) or external factors is on the rise and is strongest with impacts.

Thus it would be even paradox to make programmes accountable for impacts, on which by definition - they have the least influence! What programme actors can - and should - be made accountable for are the tasks for which they are responsible - and on carrying out these tasks in a manner that effectively influences the behaviour of other actors in the desired direction and therefore makes it more likely that impacts will be achieved. In short whether "things have been done right or the right things have been done" by programme authorities and actors - which are the main sources for identifying areas of improvement!

But this requires a different approach to monitoring, which also looks at the processes which are expected to lead to results or impacts - and not just at indicators as their final measure. This will allow to provide early information for programme actors on the likeliness of achieving results or impacts and focus can be placed on those domains, which can be influenced by them or for which they are responsible.

\section{Summary Description of Process Monitoring of Impacts}

\section{Rationale and origin of the approach}

The roots of Process Monitoring are located in development aid, where in recent years continuous discussion has taken place about the lack of project impacts and the weaknesses of monitoring systems which essentially focus on inputs and outputs. Detailed planning of activities and monitoring progress of their implementation on the basis of predetermined indicators have proved highly insufficient to observe the actual achievement of objectives and impacts. On the contrary: because of the narrow focus on (short-term) activities and a few quantified indicators the (medium and long-term) processes which are needed in order to achieve objectives / impacts tend to be largely neglected.

As a reaction to these criticisms and shortcomings considerable attempts were made to develop new methods for impact analysis and monitoring, which do not observe whether implementation is in line with original plans, but rather assess performance under complex and dynamic circumstance. The two most important and promising - approaches are: 
- Impact - oriented Monitoring ${ }^{1}$ :

The aim of this approach is to steer the implementation of projects by continuously observing whether they are likely to achieve expected impacts. To this end monitoring is oriented on impacts throughout the entire implementation chain and therefore the likeliness of impacts can already be observed at early stages of implementation. A clear distinction is made between those components for which a project is directly responsible (= activities, outputs) and results or impacts, which take place because use is made of these outputs, for which causal or plausible connections can be identified.

\section{- "Outcome Mapping"2.}

The basic assumption of this approach is that implementation partners ("boundary partners" ${ }^{6}$ ) are the main actors responsible for achieving intended changes, supported by a project (e. g. through temporary access to resources, ideas). Partners are assessed in relation to their progress in achieving objectives and becoming more effective, but not with regard to the actual achievement of expected impacts. Emphasis is placed on those outcomes, which are decisive factors for the achievement of results and can be directly influenced by a project: The quality of activities, organisational procedures, changes in the behaviour of partners or target groups.

Process Monitoring of Impacts is a blend of these two approaches and adapts them to the needs for monitoring projects or programmes in regional / structural policy mentioned above:

- The primary process for achieving objectives is constituted by activities, behaviour or communication of actors (=implementation partners), who are supported through a project / / programme with the purpose of producing intended effects.

- Assuming that projects / programmes are open, complex process, their effects cannot be determined in advance and are essentially shaped by the actors involved, their values, responsibilities, access to resources and power to influence others.
- Effects are also influenced by external factors, whose importance tends to increase with the distance to project activities and outputs (in terms of time and functional relation). Thus focus is placed on immediate impacts (= results), which are directly connected to the use of outputs.

\section{Brief description of the method}

The method builds on the basic assumption that inputs as well as outputs have to be used by someone in order to produce desired effects. Thus focus is placed on the actual use of inputs or outputs by partners, project owners, target groups etc., which is considered decisive for the achievement of effects and can be influenced by the operators of a project / programme.

Depending on the degree of use and the connection with the project / programme under study, the actual (or expected) effects are classified as:

- Outputs: They are due to direct use of inputs by project owners, closely influenced by activities and implementation mechanisms of a project / / programme.

- Immediate impacts (= results): Due to direct use of outputs, which is clearly linked with the project / programme and thus can also be directly influenced (although other factors can be important as well). A result should also be closely related to specific objectives (ideally the two should be identical).

- Impacts: Due to indirect use of outputs, which cannot be causally linked with the project/programme (attribution gap), but can at least be made plausible. Impacts normally relate to higher level objectives and are much more influenced by external factors.

The core task is to identify the likely connections between inputs, outputs, results and impacts and to check during implementation whether these links remain valid and actually take place. The following figure constitutes the framework for Process Monitoring of Impacts and illustrates how the notion of "use" can be inserted into a logical diagram of impacts:

\footnotetext{
${ }^{1}$ This approach is essentially used in German Development Aid, notably by Bundesministerium für Zusammenarbeit (BMZ) and Gesellschaft für Technische Zusammenarbeit (GTZ).

2 This approach has originally been developed in Canada, notably by the International Development Research Centre (IDRC).
} 
Figure 3 - Logical Diagram for Process Monitoring of Impacts

The degree of use is also closely related to the time dimension: outputs are by definition the first phenomena which can be observed as a consequence of programme / project inputs or activities, followed by results and impacts (although they can take place simultaneously, especially if their unintended aspects are also taken into account!)

On the other hand, there is usually a trade-off between the influence of a programme / project and external effects over time: external effects are least felt with outputs and are strongest with impacts, whereas the influence of a programme / / project decreases over time. Thus it would be even paradox to make programme / projects accountable for impacts, on which they have the least influence!

It is proposed that Process Monitoring of Impacts consists of four main steps:

1. Identify areas of intended effects (results, impacts):

When Process Monitoring of Impacts is applied with on-going projects / programmes, most of this information can be obtained from existing documents (but sometimes the distinction between results and impacts needs to be refined based on the definitions given above).
Priority areas can be selected, which are considered crucial for successful implementation and where information from Process Monitoring of Impacts can be particularly useful (e. g. results which are particularly relevant, outputs whose actual use is crucial - or doubtful).

2. Derive / agree on hypotheses for the achievement of effects:

Make assumptions about how inputs / outputs are used and by whom in order to produce intended effects. These assumptions can be based upon past experience, logical connections or professional knowledge.

They should be described as processes (activities, behaviour or communication patterns of partners, target groups etc.) which constitute the links between the activities of a project / programme and intended results and impacts.

3. Define areas of observation to monitor these processes:

These hypotheses must be observed to test whether they actually take place during implementation. Important questions for this 
purpose are: who is expected to act or change? How much? Until when?

Observation might require the definition of milestones or indicators. However, these indicators will mostly be qualitative and considered as a product of preceding processes.

\section{Data assembly and interpretation:}

Process monitoring will most likely be a task distributed among several actors, thus responsibilities for the collection of data and information need to be defined. Procedures are influenced by the time requirements, available budget and work routines (can data collection be coupled with other activities?).

Care should also be taken to capture as much as possible the entire range of effects which can be observed (i. e. unintended or unexpected effects) and to regard deviations from intended routes not a priori as negative phenomena, but deal with them in a more differentiated manner. Because differences between plan and implementation as well as exceptions or unexpected effects are important sources of information for learning and improving implementation, as they can help to identify weaknesses, point at possible alternatives or lead to new solutions.

Important questions to be answered by data analysis: Are original assumptions about use of outputs still valid? What are specific problems or weaknesses in this respect? Should original assumptions or even intended results be modified? What can operators do to improve use of outputs? How can the behaviour of direct addressees be influenced more effectively in the intended directions? What can be done to curb unintended effects?

\section{Austrian experience in applying Process Monitoring of Impacts}

The Austrian Federal Chancellery (Division for Co-ordination of Spatial and Regional Policies) has commissioned ÖAR-Regionalberatung with an action-research project to identify and test alternatives to current monitoring practice in Structural Funds.
The project started in October 2004 with the primary focus to test the applicability of "Process Monitoring of Impacts" for trans-national co-operation projects. These projects, which are cofunded by INTERREG IIIB Programmes, are faced with specific complexities in their implementation as well as unsatisfactory and cumbersome requirements for monitoring and reporting. Based on these pilot-experiences, it was also intended to reflect on a more widespread application of "Process Monitoring of Impacts" for SF-Programmes altogether.

Incidentally the author was also able to test the use of "Process Monitoring of Impacts" in other evaluation assignments, notably the on-going evaluation of an Austrian Objective 2 Programme and INTERREG IIIA Programmes on Austria's borders with new Member States.

These pilot applications are briefly described below and their main conclusions are summarised in the next section.

\section{Application with INTERREG IIIB Projects}

Present monitoring and reporting in IIIB Programmes is excessively focused on activities and outputs, which serves well to hold projects accountable to implement their original plans, but neglects the need to adapt to changing circumstance and to ultimately achieve project objectives and results. Project owners are faced with specific complexities in their implementation as well as unsatisfactory and cumbersome requirements for monitoring and reporting.

This situation was the reason for choosing INTERREG IIIB projects as pilot applications of Process Monitoring of Impacts. For these pilot applications care was taken to use as much as possible information, which was already contained in the project application and thus constitutes the base for reporting. For the representation of key processes diagrams were used, which also facilitated communication and joint reflection of involved actors. The graphic representations which were developed are based on conventional impact diagrams and can be used with computers (power-point) or with pin-boards (meta-plan technique).

The figures on the page below show the consolidated results of the pilot application of 
the INTERREG IIIB (CADSES) project TECPAR$\mathrm{CNET}^{3}$. They are presented in two figures, one page for Results and the other one for Impacts. The "use" column contains those processes which are assumed to be crucial for achieving expected results (arrows show the intended links). The impact page contains those assumptions which have been selected because they appear crucial for achieving expected impacts. They are identical to some of the assumptions on the "result page" or rather represent the final stages of some of the processes for using outputs.

Figure 4 - Process Monitoring of Impacts for INTERREG IIIB project TECPARKNET

\footnotetext{
3 This project aims at co-operation of Science and Technology Parks in the "Future Region" co-operation area. By creating links among existing parks it is expected to upgrade the level of economic and social integration in this area located at the interface between old and new Member States and lay the foundation for a long-term network.
} 


\section{Application with INTERREG IIIA Programmes}

In principle Process Monitoring of Impacts can also be applied in programmes for cross-border co-operation, both at project or at measure level. The author is responsible for the on-going evaluation of the INTERREG IIIA Programme Austria-Slovenia, where several case studies were carried out in the autumn of 2004 to assess the progress made by selected groups of projects towards achievement of results and impacts.

In these case studies Process Monitoring of Impacts was used as analytical framework, and here as well maximum used was made of information contained in programme documents, project applications and reports. The main steps of this exercise were:

- Interviews with project holders - and partners on the other side of the border - to assess the (actual or likely) contribution towards measure level objectives, based on impact indicators defined in the Programme Complement. In addition, information was collected on results which have been obtained so far (expected/ /unexpected) or how outputs are/will be used to achieve impacts.

- Information gathered from all projects within a certain measure was aggregated to provide a comprehensive picture on the likeliness for achieving measure level objectives and to outline the main arguments which support this assessment.

Based on this analysis it was possible to identify the key processes (behaviour, activities) across projects which are responsible for achieving results. This information was presented to the Joint Steering Committee in Dec. 2004.

\section{Application with Objective 2 Programmes}

In a similar way Process Monitoring of Impacts can also be applied in other SF-Programmes, again at various levels (projects, measures, priorities). Since the author is carrying out the on-going evaluation of the Objective 2 Programme Styria, it was agreed with the Management Authority to test this approach with some of the impact assessments foreseen in the framework of this assignment. 
The method used is very similar to the one applied with INTERREG IIIB projects, i. e. maximum used was made of information contained in programme documents and project applications, only adapted to some specificities of Objective 2 Programmes.

Five measures were chosen for this pilot application, which all have "soft" characteristics and whose results are thus difficult to assess with conventional, quantified indicators (i. e. support for R\&D activities, use of Information Technology, Networks, Advisory service).

\section{Preliminary assessment in relation to current monitoring practice}

\section{Monitoring of INTERREG III B Projects}

The pilot experiences carried out so far with INTERREG IIIB projects have shown that

- The concept of Process Monitoring of Impacts is relatively easy understood by project holders, because the focus is on processes which they have to steer anyway and thus are paying attention to (at least implicitly);

- The approach can be applied without problems in on-going projects and grafted upon existing indicator systems, thus integrating - and not replacing - them;

- The time requirements are rather modest, on average steps $1-3$ can be carried out within 4 hours and thus hardly take longer than designing a complete indicator system for a projector;

- The concept can also be used without problems at measure level, providing adequate links between project outputs and their contribution to measure level objectives;

- It is advisable to use diagrams for the representation of key processes, in order to facilitate communication and joint reflection of involved actors. The graphic representation which has been developed within this project is rather simple; it can be used with computers (power-point) as well as with pin-boards (metaplan technique). Therefore it is well suited for participatory processes (e. g. workshops with partners/stakeholders).

Present reporting in the IIIB Programmes (notably CADSES) is essentially based on the achievement of output and result indicators. The table below compares current practice and Process Monitoring of Impacts, based on the pilot application for the project TECPARCNET illustrated on page 44 .

Table 1 - Comparison of Process Monitoring of Impacts with current practice in IIIB CADSES

\begin{tabular}{|c|c|c|}
\hline $\begin{array}{l}\text { Current Practice } \\
\text { (Result indicators) }\end{array}$ & $\begin{array}{l}\text { Process Monitoring of Impacts } \\
\text { (Assumptions on key processes for using outputs) }\end{array}$ & Monitoring of assumptions \\
\hline $\begin{array}{l}\text { - Nr. of accesses } \\
\text { to joint web site }\end{array}$ & $\begin{array}{l}\text { - Services on web-site are known to partners (Managers of } \\
\text { Parks/Cluster) and are used by them }\end{array}$ & $\begin{array}{l}\text { - Self assessment of partners } \\
\text { - Survey conducted with particip. } \\
\text { SME (by par-tners) }\end{array}$ \\
\hline - Nr. of innovative & $\begin{array}{l}\text { - Services on web-site are known to participating SME and are } \\
\text { used by them }\end{array}$ & $\begin{array}{l}\text { - Lead partner in collaboration with } \\
\text { partners }\end{array}$ \\
\hline SME involved & $\begin{array}{l}\text { - Target group (Innovative SME) take part in specific events (joint } \\
\text { fairs, Technology Transfer days, brokerage events) }\end{array}$ & $\begin{array}{l}\text { - Questionnaires at the end, } \\
\text { follow-up survey after events }\end{array}$ \\
\hline $\begin{array}{l}\text { - Nr. of partners } \\
\text { who use project }\end{array}$ & $\begin{array}{l}\text { - Brokerage events and TT days lead to co-operations among } \\
\text { innovative SME }\end{array}$ & - Self assessment of partners \\
\hline & $\begin{array}{l}\text { - Resources of partners are identified and bundledlntranet function } \\
\text { of website is used for cooperation among partners New products } \\
\text { or technological improvements are obtained by partner SME }\end{array}$ & $\begin{array}{l}\text { - Survey conducted with partner } \\
\text { SME }\end{array}$ \\
\hline
\end{tabular}


Comparing result indicators, listed in the left hand column, with the assumptions on use in the central column clearly illustrates the differences between the two approaches:

- Instead of counting the nr. of accesses to the joint web site it is specified who should access (e. g. partners, participating SME) and which functions should be used, in order to achieve the expected result (web-site as new instrument for co-operation);

- Instead of counting the nr. of SME involved, Process Monitoring of Impacts specifies which events SME should take part in and how these events (= project outputs) are used or combined with other outputs in order to achieve the expected result (= opportunities for co-operation for SME);

- Continuous monitoring of SME participation in these events can produce regular information on whether these events are actually used by - and useful for - the target group. Moreover, aggregating these findings will in this case also produce the required result indicator $(=n r$. of SME involved).

Stated in general terms, Process Monitoring of Impacts can provide project management at early stages with information on whether expected results will likely be achieved and what needs/could be done during implementation in order to improve the chances for their achievement.

The main challenge will be to limit the time or resources for the monitoring of assumptions. The right hand column outlines main activities in this respect and care should be taken to integrate them as much as possible into regular work routines (e. g. meetings between Lead partner and partners, meetings at partner Centres). Thus reflection on the likeliness of achieving objectives will form a continuous management task of project partners.

Compared to current monitoring practice in IIIB programmes (notably CADSES), several advantages could be noticed when applying this approach with trans-national projects:
- The information provided by Process Monitoring of Impacts responds much more to the information needs of project holders and is considered more relevant than reporting on the achievement of indicators, which primarily corresponds to the information needs of the Joint Technical Secretariat (however, little is known by project holders about the actual use of this information by the JTS!).

- Articulating key assumptions facilitates joint understanding among partners from different backgrounds on crucial features and qualities (not just the achievement of a target figure). Agreement on crucial processes helps to maintain joint focus on results among actors who are relatively autonomous in their behaviour and activities.

- In order to raise the awareness of implementing partners on intended uses and result, it is recommended to carry out the work as much as possible in collaboration with them. Moreover, they will also have an important role in monitoring processes and should equally be involved in the interpretation of data and information gathered.

- Placing emphasis on the use of outputs also helps to lay open differences in objectives among actors or between explicit and implicit objectives. The reason why specific outputs are not (or not enough) used by certain actors can be explained by their "hidden agendas", which are otherwise difficult to identify and deal with.

\section{Monitoring of SF - Programmes (e. g. Objective 2, INTERREG)}

Process Monitoring of Impacts will also differ substantially when compared to current monitoring practice in SF-Programmes. This is shown in table 4, which compares current practice and Process Monitoring of Impacts, based on the example of a measure "support for R\&D in firms", which has been presented in table 2 . 


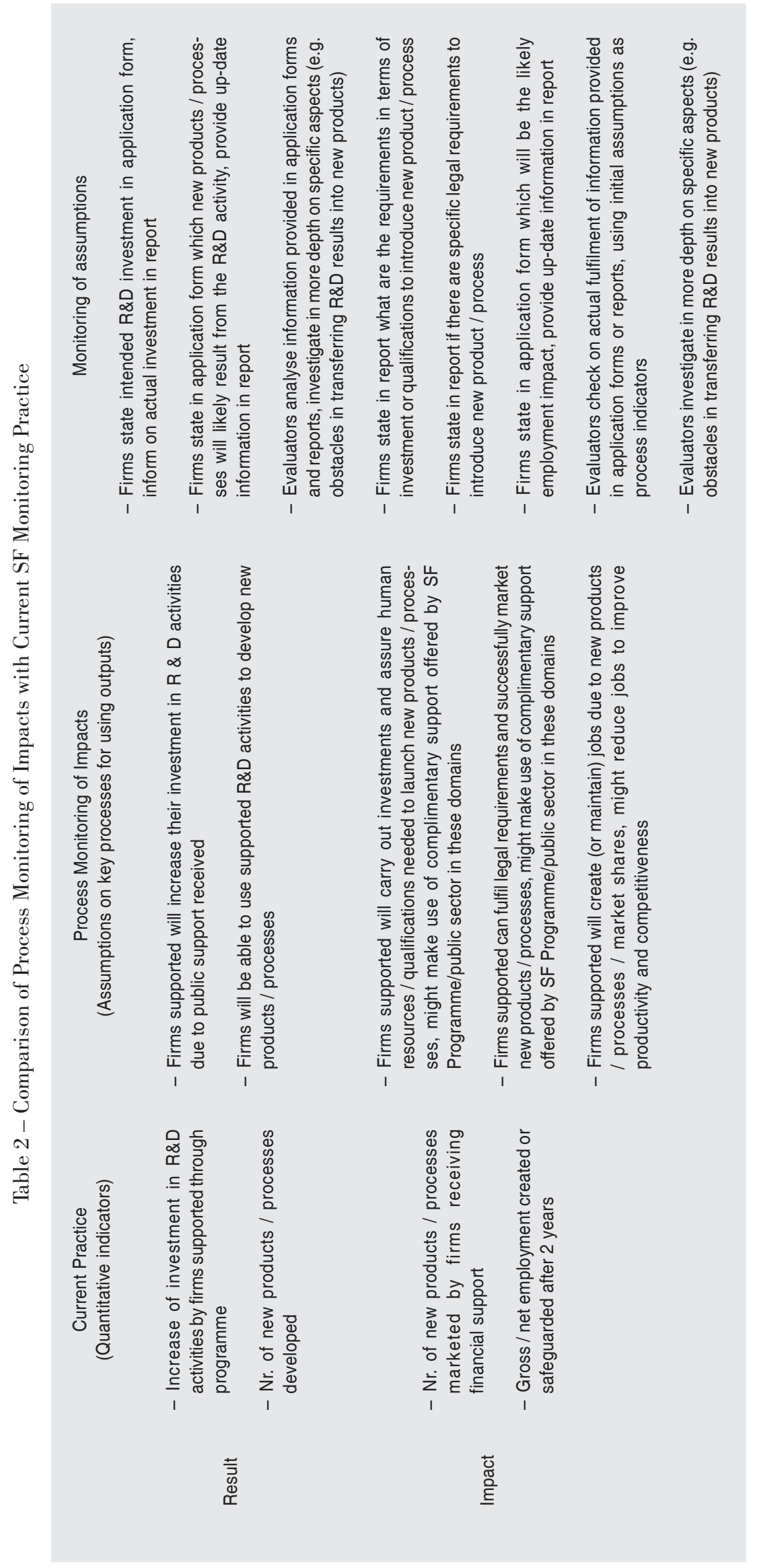


The assumptions for the achievements of effects contained in the central column can be monitored by the funding authority during implementation in several ways (see right hand column):

- Some assumptions can already be checked at the application stage (e. g. which new products will likely result from the $R \& D$ activity, are there specific legal requirements, qualification needs to introduce them? What will be the likely employment impact?).

- The supported firm can provide some information in their reports to the funding authority (e. g. new products / processes to be developed based on the R\&D activity, specific legal requirements to introduce new product / process? requirements in terms of investment or qualifications? Expected employment impact of the new product / process).

- The likely or actual achievement of assumptions can be assessed during programme evaluation, the assumptions will serve as process indicators to be validated by evaluation tools (e. g. case studies, surveys of supported firms).

- Reports as well as evaluation work should attempt to capture the entire range of effects which can be observed and should specifically ask for unintended or unexpected effects which have occurred in connection with the supported activity.

Compared to current monitoring practice in SF-Programmes, Process Monitoring of Impacts offers several advantages:

- Present monitoring systems respond to the information needs of input-driven implementation, essentially observe the implementation of activities and produce information on input (financial resources) and output. Process Monitoring of Impacts would respond to the information needs of impact-led management, observe the achievement of objectives and produce information needed to understand impact creating processes.

- Because the focus is on links and relationships, Process Monitoring of Impacts allows to identify behaviour or interaction patterns which are crucial for achieving effects. Their observation can be carried out in collaborative forms and need not demand more time from programme implementers than current monitoring practice.

- Present monitoring systems rarely contain data on result - and impact indicators which must be collected separately (e. g. through surveys, evaluators). Thus Process Monitoring of Impacts does not necessarily require more time and resources, as most of the information needed to fill in monitoring indicators can be collected in the process.

- Process Monitoring of Impacts orients the observation of programme authorities towards the achievement of objectives. By demanding corresponding information from project owners, they can also raise their awareness in the same direction, focusing attention on results and impacts can influence their behaviour in the desired direction.

- Indicators can also be used in this approach, but they are not regarded as isolated phenomena, but as products of preceding processes. Instead of treating indicators as objective "data" which have identical meaning irrespective of context, their interpretation is always based on relevant context information and the interpretations of different actors.

- Present monitoring systems usually provide date on results and impacts at very late stages (if at all). But with Process Monitoring of Impacts one does not need to wait to assess results until a chosen indicator is met, but understanding and observing the underlying processes can provide timely and early information if a project / programme is on the right track - or risks to miss desired results.

- Because Process Monitoring of Impacts does not assess the actual achievement of effects, but contributions towards desired changes, it is particularly suited for projects / programmes which act in an indirect way through partners. And because it is based on the observation of processes, it is well suited to monitor "soft" measures, who deal with open tasks, whose crucial qualitative features are difficult to capture by quantitative indicators. 


\section{Other uses and applications}

As was described above, the applications of Process Monitoring of Impacts in Austria so far have on one hand been limited to soft measures / projects which mainly produce intangible results difficult to capture by quantitative indicators. On the other hand, these applications were made at rather late stages in implementation, where impacts can already be observed or at least their likeliness can be assessed on rather concrete terms.

But Process Monitoring of Impacts can also be applied during early stages in implementation, whereby the focus of attention can shift from the use of outputs to the use of inputs. Referring to the example of the R\&D measure quoted above, assumptions which can be made by a funding authority include:

- Firms are aware of the need and interest of increasing their R\&D activities

- Firms are able to identify suitable project ideas and are capable to prepare applications in required time and quality

- Firms / target groups are sufficiently informed about the support scheme and the modalities for submitting applications (e.g. deadlines of call for proposals)

- The support scheme is in line with business needs and the funding conditions can be met by the target groups (e. g. co-financing requirements).

By observing these assumptions, funding authorities can already identify at very early stages whether the proposed support scheme will likely lead to the desired outputs ( $=$ nr. of projects by target group) and can take steps to improve the conditions for the use of inputs (e. g. awareness campaign, technical assistance, promotional efforts, modification of procedures).

Process Monitoring of Impacts can also be applied with "hard" measures/projects (e. g. infrastructure, tangible investments) which can normally be captured quite well by quantitative indicators. But a major inconvenience is often that information for result / impact indicators arrives too late and is therefore not suitable as a management tool. Here Process Monitoring can produce relevant informant rather early and signal areas of improvement to management. In the case of a road construction project, assumptions which can be made on the use of inputs include:

- Feasibility study has been carried out, demonstrating the need for the road and providing an overall positive assessment of the proposed project

- Land use permits have been obtained and environmental assessments are concluded

- Objections by concerned citizens can be overcome in due time and satisfactory manner

- Co-financing has been assured and public tenders have been concluded.

The favourable preliminary assessment stated above is made from a professional point of view and highlights the advantages of Process Monitoring of Impacts in relation to current monitoring procedures. Although this approach would predominantly mean an improvement of monitoring practice at the level of professionals, it can also make important contributions to other groups: it can assist administrators by providing a sounder understanding of expected effects, or politicians by providing early information whether impacts will be achieved.

\section{Applying Process Monitoring of Impacts with Structural Funds in the New Programme Period ${ }^{4}$}

\section{General considerations}

Based on the experience gained so far in Austria, Process Monitoring of Impacts appears well suited to be applied in monitoring SF-Programmes.

- It is a very appropriate approach to address the challenges posed by the new objectives, in particular those which will be relevant for Austria "Regional Competitiveness" and "Territorial Cooperation". The content of these programmes will

\footnotetext{
4 This Chapter takes into account recent proposals by the EU Commission for the new programming period 20072013 , notably the Working Papers on indicators and Ex-ante Evaluation
} 
mainly consist of soft measures and "open" tasks, whose crucial processes are difficult to be captured by present Monitoring Systems which are solely based on indicators.

- As it orients the observation of programme authorities and other involved actors (project owners, implementing partners) towards the achievement of objectives, it can complement present in-put driven Monitoring Systems with an impact-led approach. This is in line with Commission proposals to reorient the entire SF programming system towards impact.

- It can lead to a clearer distinction of monitoring activities in line with the logics and information needs of the actors involved:

- The electronic Monitoring System will contain controllable and quantifiable data which is formally required by programme administrators at higher levels (managing authority, EU Commission) and for reporting to the political level or a wider public.

- Process Monitoring of Impacts will provide qualitative and quantitative information for implementing agents (within or outside the public administration) and for professionals. These activities take place outside the formally required Monitoring System, provide feed-back and facilitate learning in order to improve implementation.

However, in order to be applied most effectively there needs to be a shift in resources and attention on several aspects:

- From planning to managing implementation: this is in line with Commission proposals to simplify programming and provide utmost flexibility for evaluation. But programme authorities in Member States must consciously decide to spend less time and resources for preparing programmes and instead on monitoring and evaluation. Process Monitoring of Impacts will best be carried out if embedded in a framework of on-going evaluation, which has already been introduced in Austria in the present period.

- From monitoring of (quantifiable) indicators to monitoring of processes: differentiating monitoring activities as proposed above should lead to a substantial reduction of data in the electronic Monitoring System. This will in turn reduce the workload of administrators to fulfil formal requirements and should allow to spend more time and resources to monitor processes and establish a learning system based on Process Monitoring of Impacts.

- From quantifying data to identifying crucial processes: defining the core impact assumptions helps to clarify the intervention logic and provides orientation for a series of implementation issues (e. g. assessing and selecting project proposals, identifying information needs) It is also the basis for any sound quantification and thus it should be given priority. Whether quantifications take place (and are even useful) is a secondary issue and will depend on many other factors, e. g. nature of the intervention, availability of baseline data, experience of implementing agents.

\section{Specific tasks and aspects to be considered}

In line and in addition to what has been said above, the following recommendations can be made in order to facilitate the application of Process Monitoring of Impacts:

\section{Programming and ex-ante evaluation}

- Precision in defining measure level objectives:

During the programming process (financial) inputs will be determined and a hierarchy of objectives established (at programme, priority and measure level). Expected outputs will mainly consist in the number and types projects to be funded with the resources made available by the programme. And other effects to be achieved are classified either as results or impacts.

For Process Monitoring of Impacts to be applied, the correspondence between effects and objectives is of particular importance:

- Measure level objectives should correspond as much as possible with expected results, in order to make a clear causal connection and define them as direct use of outputs. Thus they should be in line with the timeframe of the programme, 
the competence or responsibilities of implementing agents and intended beneficiaries and the nature of the measure respectively projects to be funded (output).

- Impacts on the other hand, should correspond to higher level objectives, i.e. those defined at priority and programme level. This way at least plausible connections can be established between the two, which are subject to verification either during the programme's implementation or in the framework of an ex-post evaluation after the end of a programme.

- Formulate key process assumptions at measure or priority level:

Once the hierarchy of objectives / effects has been established and the expected results and impacts are known, key assumptions about their achievement can be made. Although for Ops it will only required to define priorities, it is probably useful to do this exercise at the level of (indicative) measures, especially if the measures contained in one priority address quite different topics or aim at different target groups.

This task can either be carried out as part of the programming process or (preferably) in the framework of the ex-ante evaluation. In this case the ex-ante evaluator works with programme authorities to identify core process assumptions based on the hierarchy of effects defined beforehand by the programme authorities.
Process assumptions should primarily be identified for results, but if considered useful this exercise can also done for impacts - or for outputs, which might be particularly helpful in the early stages of programme implementation.

At this point it is also advisable to select priority areas, which are either considered crucial for successful implementation and where information from Process Monitoring of Impacts can be particularly useful (e.g. results which are particularly relevant, outputs whose actual use is crucial - or doubtful).

When the assumptions point at linkages between individual measures (e.g. if an expected use of outputs will the contribution to another measure or follow-up projects funded from another measure), a synthesis figure should be established at priority or even programme level, which contains the chains of effects that are expected to take place across measures.

- Define quantifiable indicators for Monitoring System:

Based on the process assumptions some indicators will be defined, which are to be included in the electronic Monitoring System in order to collect quantitative data on them. These indicators will likely represent the end-point of preceding process chains. As mentioned below, these indicators will predominantly be on outputs, plus a few selected result indicators.

Figure 5 - Chain of process assumptions 


\section{Electronic Monitoring Systems}

This will continue to be an important source of information, but contents should be streamlined and focused on those aspects, where quantified data is meaningful and collection can be managed quite easily, based on sound standards in order to facilitate comparison /aggregation and avoid ambiguity in interpretation.

Thus the main contents will be:

- Inputs: This is key information for sound financial management and fulfilling the $n+2$ rule (e.g. data on commitments, disbursements, funding ratio and their comparison to financial tables).

- Outputs: They should entirely be monitored via indicators, as this will also provide baseline information for Process Monitoring. Thus the Monitoring System will to a large part consist of output indicators, which can normally be collected quite easily from all projects supported.

- Results: Only a very limited number of "core" indicators should be contained, which clearly are in line with the information and reporting needs of programme administrators at higher levels (Managing Authority, EU Commission).

- Impacts: If impact indicators are formulated, they should not be contained in the Monitoring System, but treated as evaluation indicators, to be dealt with by evaluators. Thus it is not necessary to continuously obtain information on them.
Quantification should only be required on output indicators, because they offer an adequate basis for sound predictions and quantified data are readily obtainable by administrators. Quantifications of other indicators should be decided case-by-case, based on whether they are meaning- or useful.

\section{Process Monitoring of Impact}

The task for observing whether process assumptions actually take place during implementation will most likely be distributed among several actors, therefore procedures and responsibilities for collecting data and information need to be defined. Procedures are influenced by the time requirements, available budget and established work routines. A major challenge of this (and any other) monitoring approach will be to limit the work load of administrators. Time or resources for the monitoring of assumptions can be kept low by integrating this work as much as possible with activities which have to take place anyway.

The most important procedures in this respect will be:

- During the application / decision-making stage:

- Project applications: The application forms can already be designed in a manner that they serve to collect relevant information, which can be used for project assessment or constitutes baseline information to be validated during later stages in project implementation. The applications should contain questions like: what

Figure 6 - Contents of Electronic Monitoring System 
are expected outputs, how should they be achieved? How should outputs be used? By whom and for which purpose? The response categories for these questions should be structured according to the process assumptions defined at measure level, in order to facilitate treatment of information later on.

- Contacts with applicants: Programme actors who provide information or support to applicants at this stage could ask similar questions in their contacts with applicants and also instruct them on the rationale and importance for answering these questions. This way programme actors build up a stock of implicit knowledge how applicants see the way which should lead towards outputs and results - and might also discover some unexpected routes or unintended processes which have not been captured by the original assumptions.

- Conditions of funding decisions: programme actors or bodies who are responsible for funding decisions can include process aspects in their considerations and even include them as conditions, which the applicants must meet and have to inform on. This will help to focus applicant's concerns not just on project implementation, but on the achievement of results and impacts as well.
- During or at the end of project implementation:

- Intermediary Reports: these reports serve to provide on-going information on whether original process assumptions are still valid, where divergence or unexpected effects take place. They should be structured in accordance with main elements of the application form and be as standardised as possible, in order to facilitate data processing and the production of time line information.

- Final Reports: they should provide conclusive evidence whether process assumptions have actually been met or unexpected effects have taken place, but also contain information on the achievement of impacts - or the plausibility for achieving them.

- Contacts with project owners: just as during the preparation phase, they can be used to gather information how applicants see their progress towards outputs and results - and might also serve to discover unexpected routes or unintended processes which have not been captured by the original assumptions.

The major information sources which can be used by programme management for Process Monitoring of Impacts can be summarised as follows (for each stage of the project cycle):

Figure 7 - Main information sources 
Identifying the most appropriate forms for data assembly is an important task of programme authorities, which should be undertaken at rather early stages, possibly with external assistance (e. g. as part of the ex-ante evaluation). And feasible solutions must be found for cases which pose a particular challenge due to the large number of projects to be treated (e. g. sampling, electronic processing of information).

Process Monitoring of Impacts implies a major shift in accountability, as project owners are essentially made accountable to achieve outputs and pursue their intended uses. Thus they would gain more flexibility in implementation and do not have to provide detailed account of their activities. On they other hand they will be obliged to inform programme authorities in due time if the achievement of outputs is at risk and adaptations are needed (in terms of funding, timing or even outputs). Moreover, this would considerably reduce paper work and bureaucratic obligations:

- Shorter Project Applications: they should essentially contain a description of project content (background, objectives, target groups and expected effects) and an outline of the main processes needed to achieve them, including an indicative action plan.

- Simplified and standardized Reporting: reports should inform on context changes and the quality of cross-border co-operation, but also on progress towards outputs and the achievement of expected results or impacts. Reporting standards need to be applied by all sides and rules for the exchange of information on project implementation should be agreed.

\section{Role and use of evaluation}

During the application / decision-making stage, process aspects should be included as criteria for the assessment of applications: are the expected outputs in line with assumptions formulated at measure level, does their foreseen use contribute to achieving results or impacts defined at measure level? In this way applications can be rated according to their likely contribution for achieving objectives at measure or priority level.
Later on evaluation can be used to analyse and interpret information in three ways:

- Analysis of monitoring data:

Evaluators can assess delivery of (financial) inputs and quantify progress made towards the achievement of co-operation quality, outputs as well as some selected results by analysing quantified data contained in the Electronic Monitoring System.

- Analysis of information collected:

Evaluators can assess progress made towards results or impacts at measure or priority level based on the information sources mentioned above (e. g. applications, reports). This work can be done in collaboration with other actors (e. g. Programme Administration). An important task in this respect will be to identify main differences from original plans and the emergence of unintended effects.

- Carry out additional analysis:

In order to collect more qualitative information on selected issues, additional activities can be undertaken (e. g. questionnaire surveys, interview, focus groups). And they can carry out detailed impact analysis to further explore effects achieved. However, impacts should be assessed as specific as possible (e. g. for a group of projects, a measure/ /priority, a sector or a territory). In this way, the complexity of interventions can best be taken into account (incl. spill-over, synergy and displacement effects) and the information is most likely to correspond with the needs of implementing agents.

Process Monitoring of Impacts will be most effective if evaluations are carried out in a climate of partnership, mutual respect and trust, therefore evaluation designs should focus on joint reflection and learning, based on these qualities. Furthermore, it would be advantageous if done in a framework of on-going evaluation, which is build around the information needs (and evaluation questions) of programme administrators and whose timeframe is sufficiently flexible. 
To sum up, Process Monitoring of Impacts leads to the establishment of a comprehensive Management Information System, which combines existing elements and procedures in an interconnected manner: electronic Monitoring Systems, Applications, Reports, Contacts / meetings with applicants, project assessment, evaluation. The innovation therefore lies not in the individual elements, but in their new and creative combination. Thus Process Monitoring of Impacts essentially consists in a coherent framework for knowledge management at programme level.

The figure below shows the main elements, distributed at various levels and over the time sequence of the project cycle.

Figure 8 - Main elements of the information system used by Process Monitoring of Impacts

\section{Bibliography}

CARDEN Fred, Earl Sarah, Smutylo Terry, 2001, Outcome Mapping, Ottawa, International Development Research Centre.

GTZ, 2004, "Wirkungsorientiertes Monitoring - Leitfaden für Vorhaben der Technischen Zusammenarbeit", Eschborn, GTZ Stabsstelle Unternehmensentwicklung.

GTZ, 2003, "Wirken in neuen Zusammenhängen”, Eschborn, Stabsstelle Stabsstelle Unternehmensentwicklung.

KUBY, Thomas, VAHLHAUS, Martina, 2003, "Orientierungsrahmen für das Wirkungsmonitoring in Projekten der
Wirtschafts-und Beschäftigungsförderung unter besonderer Berücksichtigung armutsmindernder Wirkungen", Eschborn, GTZ Abteilung 41 Wirtschafts- und Beschäftigungsförderung.

HUMMELBRUNNER, Richard, HUBER Wolf, ARBTER Roland, 2005,"Process Monitoring of Impacts - Towards a new approach to monitor the implementation of Structural Fund Programmes", Wien, Bundeskanzleramt Abteilung IV/4.

HUMMELBRUNNER, Richard, 2005,"Process Monitoring of Impacts - Experience and proposals for use with transnational co-operation projects", Wien, Bundeskanzleramt Abteilung IV/4. 